Check for updates

Cite this: RSC Adv., 2018, 8, 24154

Received 1st May 2018

Accepted 27th June 2018

DOI: $10.1039 / c 8 r a 03735 c$

rsc.li/rsc-advances

\section{The theoretical chemical calculations clarify the mechanism of beta-alkylation of 1-phenylethanol with benzyl alcohol catalyzed by iron(II) acetylacetonate methods $\uparrow$}

\author{
Wei Feng, ${ }^{a}$ Junfeng Zhao, ${ }^{c}$ Aiwen Wei, ${ }^{a}$ Dandan Zhang, ${ }^{a}$ Huiling Liu, (DD *a \\ Xuri Huang*a and Kai Sun*b
}

Iron(II) acetylacetonate was suggested to be a better catalyst of the $\beta$-alkylation of 1-phenylethanol with benzyl alcohol to form 1,3-diphenyl-1-propanol. DFT calculations have been performed to study the internal mechanism, the structures of intermediates and transition states, and the exchange of electronic density in detail. The energetic results show that this $\beta$-alkylation reaction proceeds via the hydrogen autotransfer mechanism and the catalytic cycle includes three sequential stages: (1) alcohol oxidation to produce aldehyde associated with hydride anion transfer, (2) cross-aldol condensation to form a chalcone and (3) chalcone reduction with multi-step hydrogenation. In order to study whether the only by-product, water, has clearly influenced the reaction, eight catalyst hydrogenation pathways and four catalyst dehydrogenation pathways have been studied. We are delighted to find that the presence of the only by-product, water, can significantly increase the reduction energy barrier of dihydrochalcone. The energy barrier of the catalyst's hydrogenation is less than $6 \mathrm{kcal} \mathrm{mol}^{-1}$. Our calculation results are fundamentally coincident with the experimental detections, and suggest that the crossing-coupling reaction occurs through a reliable mechanism. Two dihydrochalcone catalysts were designed on the basis of how the $\beta$-alkylation reaction proceeds.

\section{Introduction}

The alkylation reaction is one of the most studied reactions in organic synthesis and catalysis due to its importance in carboncarbon bond creation and long chain compound formation. Various alkylating agents are used in this process such as halohydrocarbon, sulfonate, and carbonyl compounds. ${ }^{1-5}$ However, most reactions generate considerable amounts of side products or waste. How to increase the atom-efficiency of the creation of carbon-carbon bonds is a key step of modern green chemistry. Alcohol, as one of the most common reagents, has been used in carbon-carbon bond formation reactions. In 2015, Jian and MacMillan developed a dual catalyst system that directly installs alkyl group fragments containing singly bonded carbon and

${ }^{a}$ Laboratory of Theoretical and Computational Chemistry, Institute of Theoretical Chemistry, Jilin University, Technology Building of Jilin University, Liutiao Road 2, Changchun 130023, China.E-mail: huiling@jlu.edu.cn; huangxr@jlu.edu.cn ${ }^{b}$ School of Pharmaceutical Sciences, Jilin University, Changchun 130021, China. E-mail: thomassk@jlu.edu.cn

${ }^{c}$ Department of Materials, School of Technology, Yantai Nanshan University, Longkou, Shandong Province, 265713, China

$\dagger$ Electronic supplementary information (ESI) available: The atomic coordinates, DFT-based single-point energy, thermodynamics and solvation corrections of all optimized compounds studied. See DOI: 10.1039/c8ra03735c hydrogen atoms. They showed that it is possible to accomplish mild, non-traditional alkylation using alcohols as radical precursors. $^{6}$ This environment-friendly reaction aroused great interest, and more investigations using alcohols as the alkylating agents were reported. ${ }^{-9}$

The catalyst is another important factor of alkylation reaction. Most catalysts used in the alkylation reaction are mainly based on Ru, Pt, and Ir. ${ }^{10-13}$ However, these noble metals catalysts are expensive and are not easy to obtain. The use of more eco-friendly and widely abundant metals for the synthesis should be more beneficial for chemical research and industry

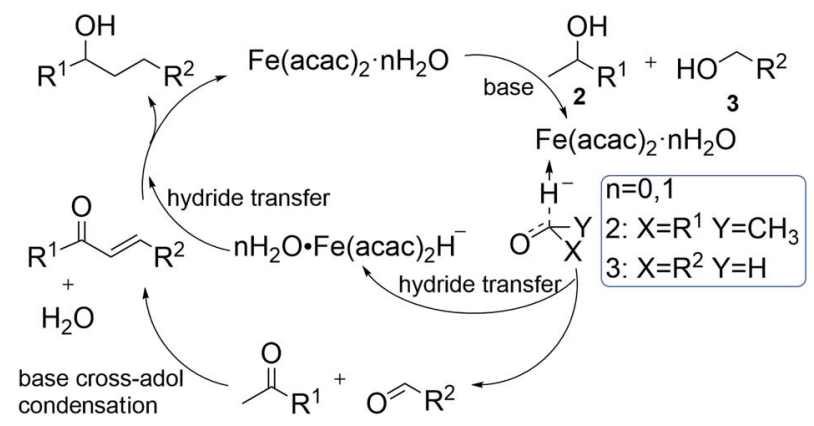

Scheme 1 Mechanistic proposed for the iron-catalyzed crossingcoupling reaction. 


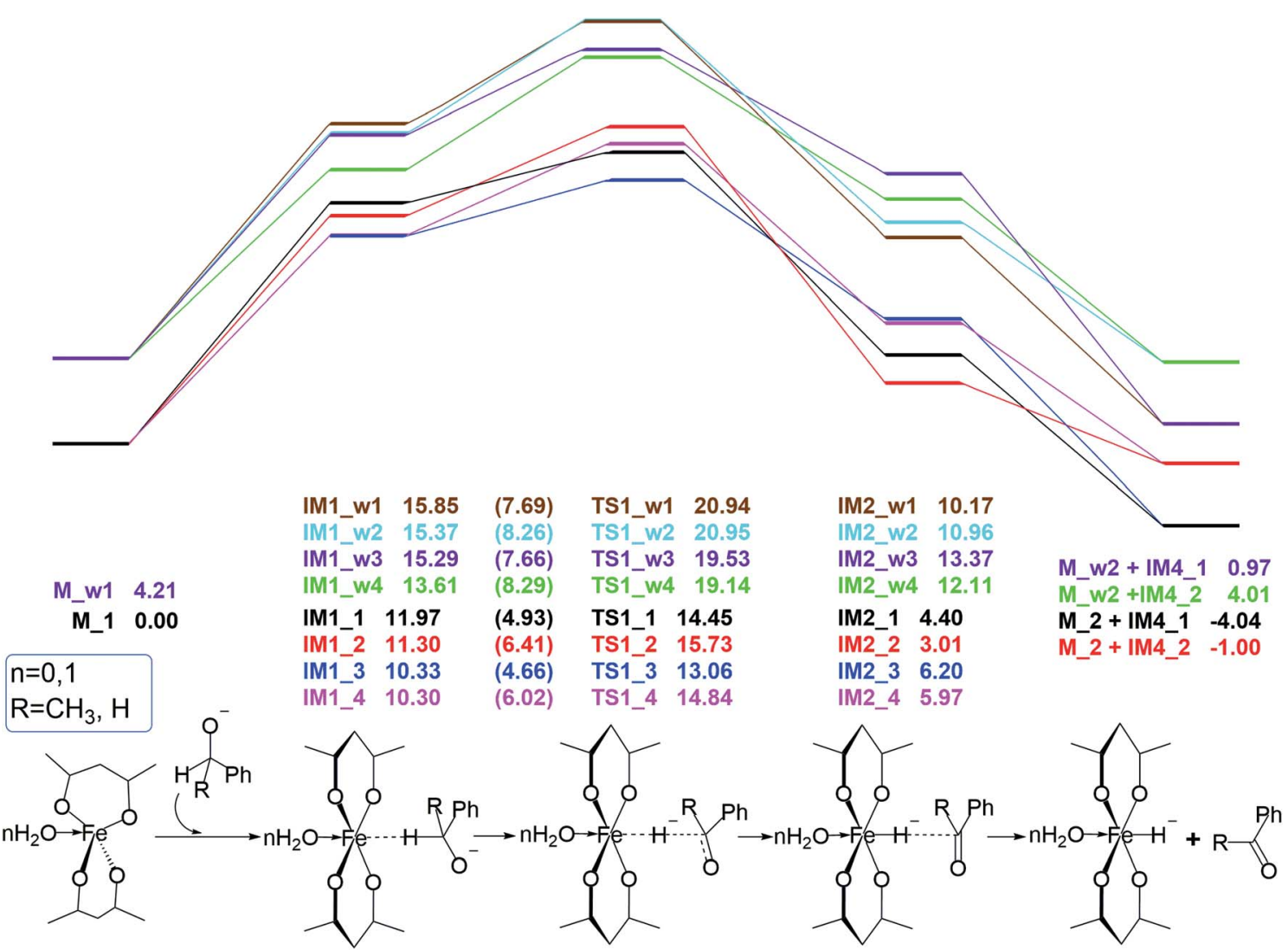

Fig. 1 Eight reaction pathways and corresponding free energy profiles of $\mathrm{H}$-adsorption step in catalyst initiation. The numbers in parentheses refer to the activation barriers.

manufacture. Iron, as the most productive metallic element on Earth, has been wildly used in alkylation reactions. ${ }^{14-16}$ Furthermore, iron as a catalyst has also been used in the alkylation reaction with alcohol as the alkylating agent. ${ }^{17,18}$

In 2012, Sun et al. found that the ferrocenecarboxaldehyde catalyst has a very good catalytic effect on the $\beta$-alkylation reaction of secondary alcohols with primary alcohols..$^{19}$ We have conducted detailed theoretical calculations on the catalytic mechanism of ferrocenecarboxaldehyde. Sun et al. are always looking for cheaper, more stable, efficient and environmentally friendly catalysts. Recently, they found that under the same reaction conditions, the inexpensive acetylacetonate catalyst can also achieve very high yields (>95\%) compared to the ferrocenecarboxaldehyde catalyst with an order of magnitude reduction. ${ }^{20}$

This microscale reaction mechanism has not been previously studied or explained. In this paper, we will use density functional method to analyze the reaction process in detail. According to our previous studies, ${ }^{21}$ a simplified plausibility process for the $\beta$-alkylation of water-involved secondary and primary alcohols is proposed in this paper (see Scheme 1).

We conducted the elementarily theoretical calculation of the mechanism of the $\mathrm{Fe}(\mathrm{acac})_{2}$ catalyzed cross-coupling reaction. It also provides inspiration and reference for the synthesis of new cheap catalysts. At the end of the article, two ideal catalysts have also been suggested to control the product selectivity. We hope that this study could provide useful information for the industrial production.

\section{Computational details}

All geometrical optimization calculations were performed using the GAUSSIAN 09 revision D.01 (ref. 22) at the level M06-L $\mathrm{L}^{23} / \mathrm{BSI}$, BSI represents the basis set combination of SDD pseudopotential for $\mathrm{Fe}$ and $6-31 \mathrm{~g}(\mathrm{~d}, \mathrm{p})$ for $\mathrm{C}, \mathrm{O}$ and $\mathrm{H}$ atoms. At the same level of theory, frequency calculations were performed to identify the stationary points as real minima or transition states and to provide thermal corrections to the enthalpies and Gibbs free energies at $463.15 \mathrm{~K}$. Intrinsic reaction coordinate (IRC) calculation $\mathrm{s}^{24}$ were carried out to confirm the correct connections between a transition state and its forward and backward reactive intermediates. ORCA 3.0.3 (ref. 25) was used to perform the single-point calculations on previously optimized geometries. In order to obtain a better estimation of total electronic energies, the double-hybrid PWPB95 functional, ${ }^{26}$ including the D3 dispersion correction ${ }^{27,28}$ due to Grimme and the Becke-Johnson damping function, and the large basis set def2-TZVPP ${ }^{29}$ were adopted. We have verified the energies of the key species including diffuse functions in the basis set, and the results didn't changed greatly. In order to reduce the computational time, diffuse functions didn't included in and the resolution-ofidentity (RI) technique is used for accelerating both selfconsistent field (SCF) process and second-order perturbative correction part. The loss of accuracy due to above two factors is negligible. Schematic frontier molecular orbital (FMO) diagrams were represented by quasi-restricted orbitals, and 

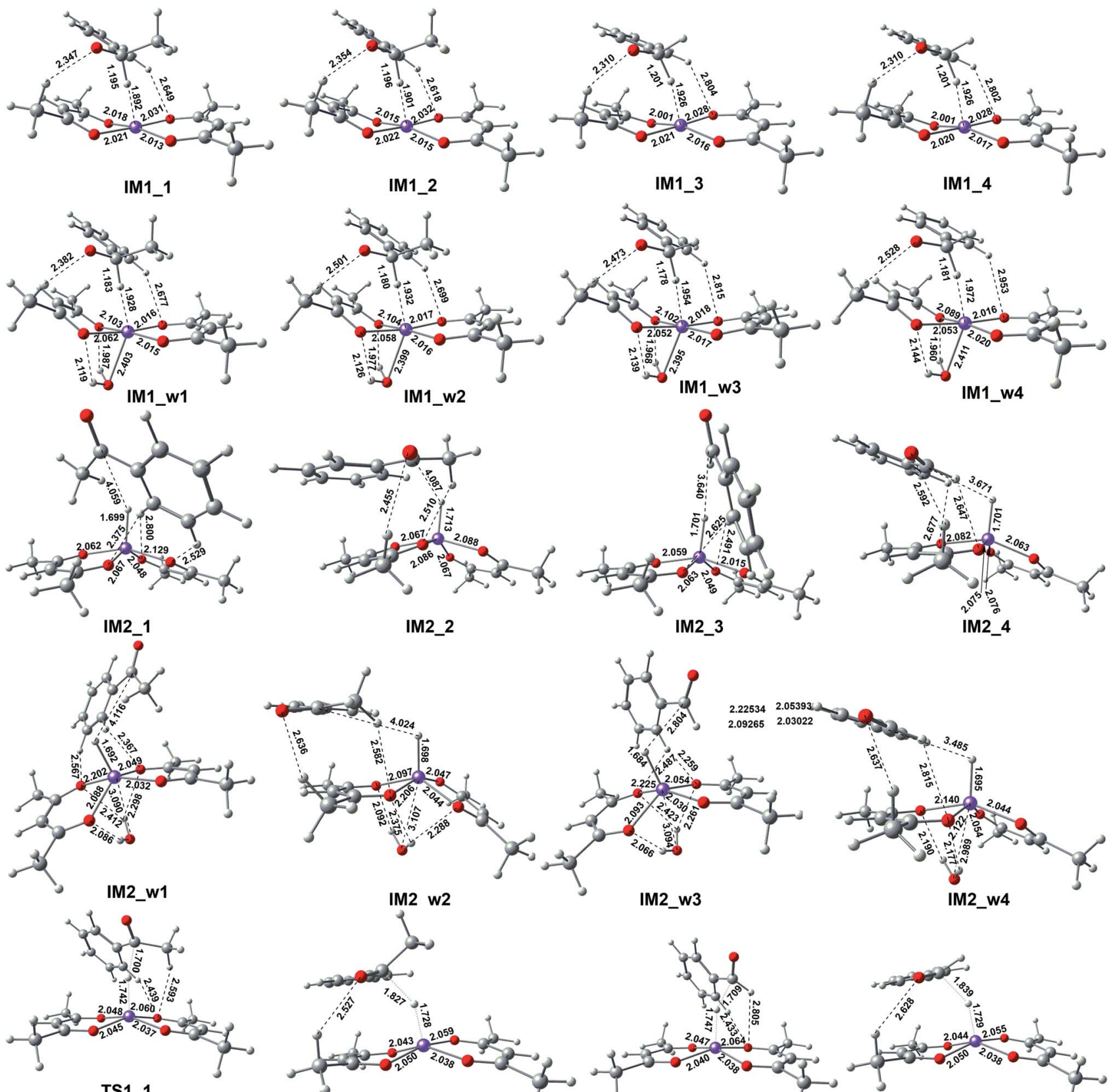

TS1_1
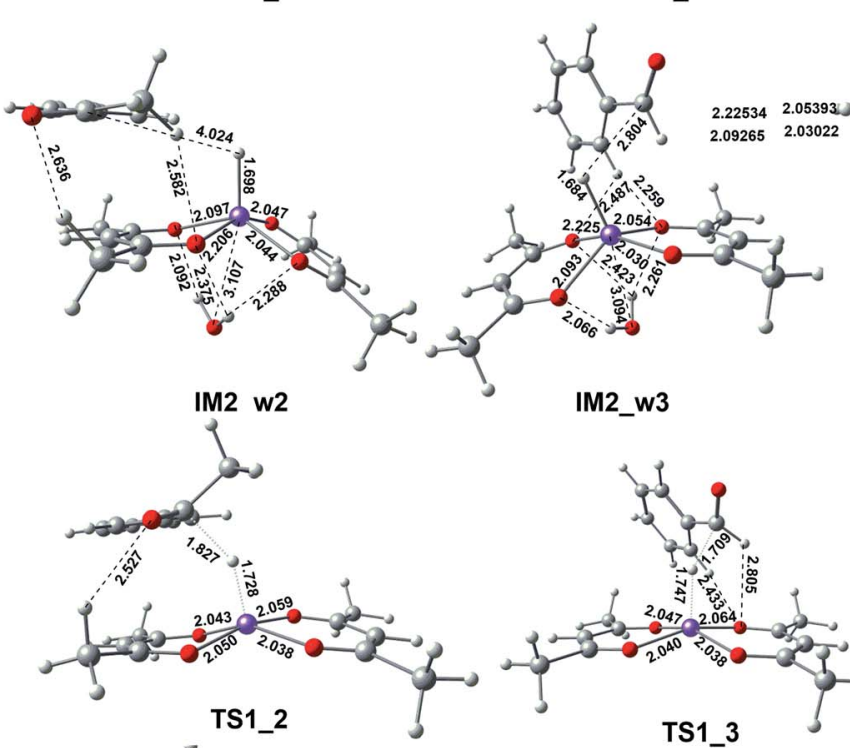

IM2_w3
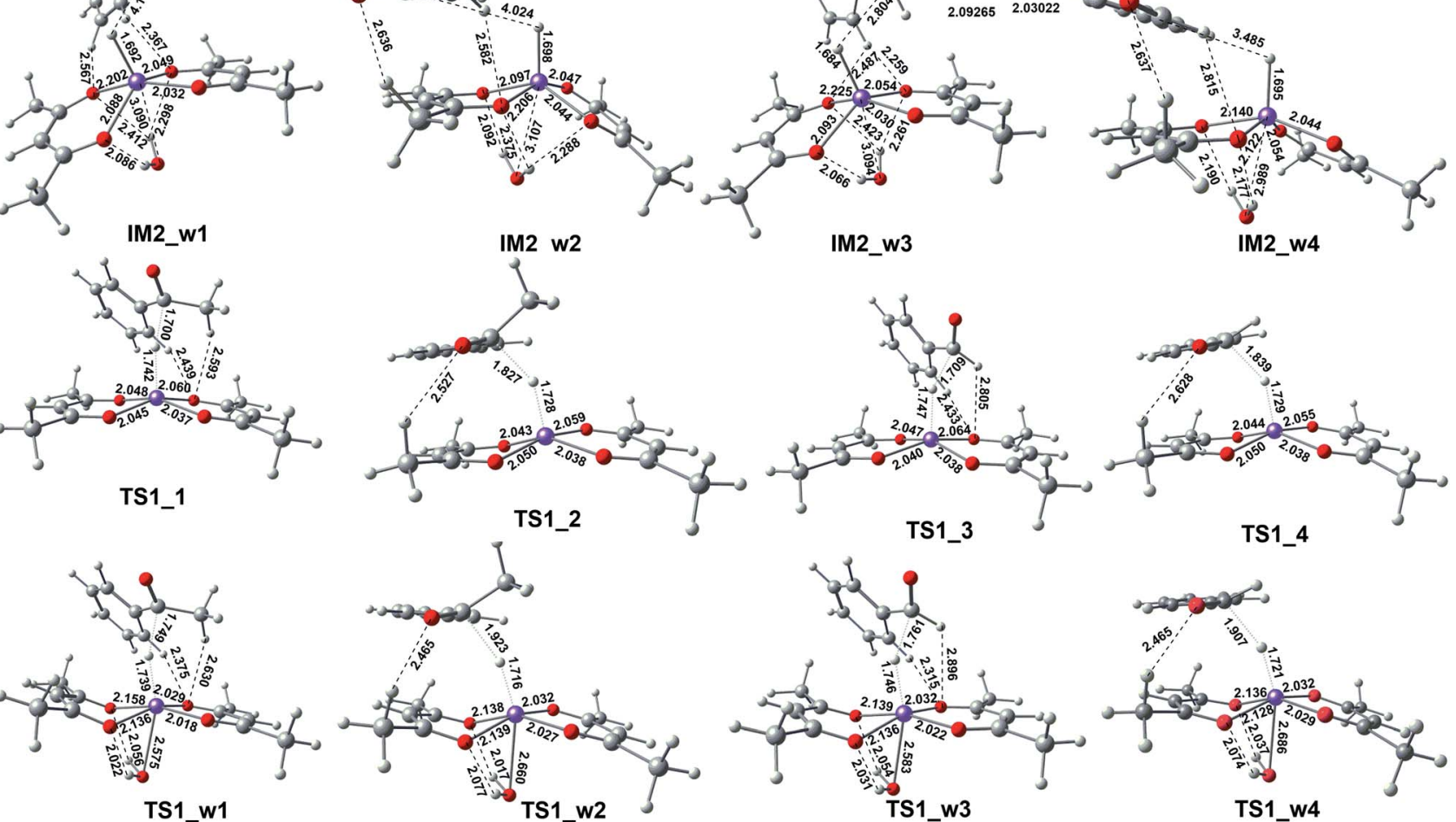

Fig. 2 Optimized geometries of the complexes with selected bond distances (in Å).

were plotted using Chimera. ${ }^{30,31}$ Natural population analysis (NPA) charges were calculated by the NBO 3.1 module embedded in Gaussian 09 program.

The solvation free energies of the optimized geometries were calculated at the M05-2X $\mathrm{X}^{32} / \mathrm{BSII}$ (SMD, $p$-xylene) level (BSII designates the basis set combination of SDD pseudopotential for the Fe atom and 6-31G(d) for the other atoms; SMD corresponds to Truhlar and coworkers' solvation model which does an IEFPCM calculation with radii and non-electrostatic terms). All the energy that appears in this article is Gibbs free energy in $\mathrm{kcal} \mathrm{mol}^{-1}$. 

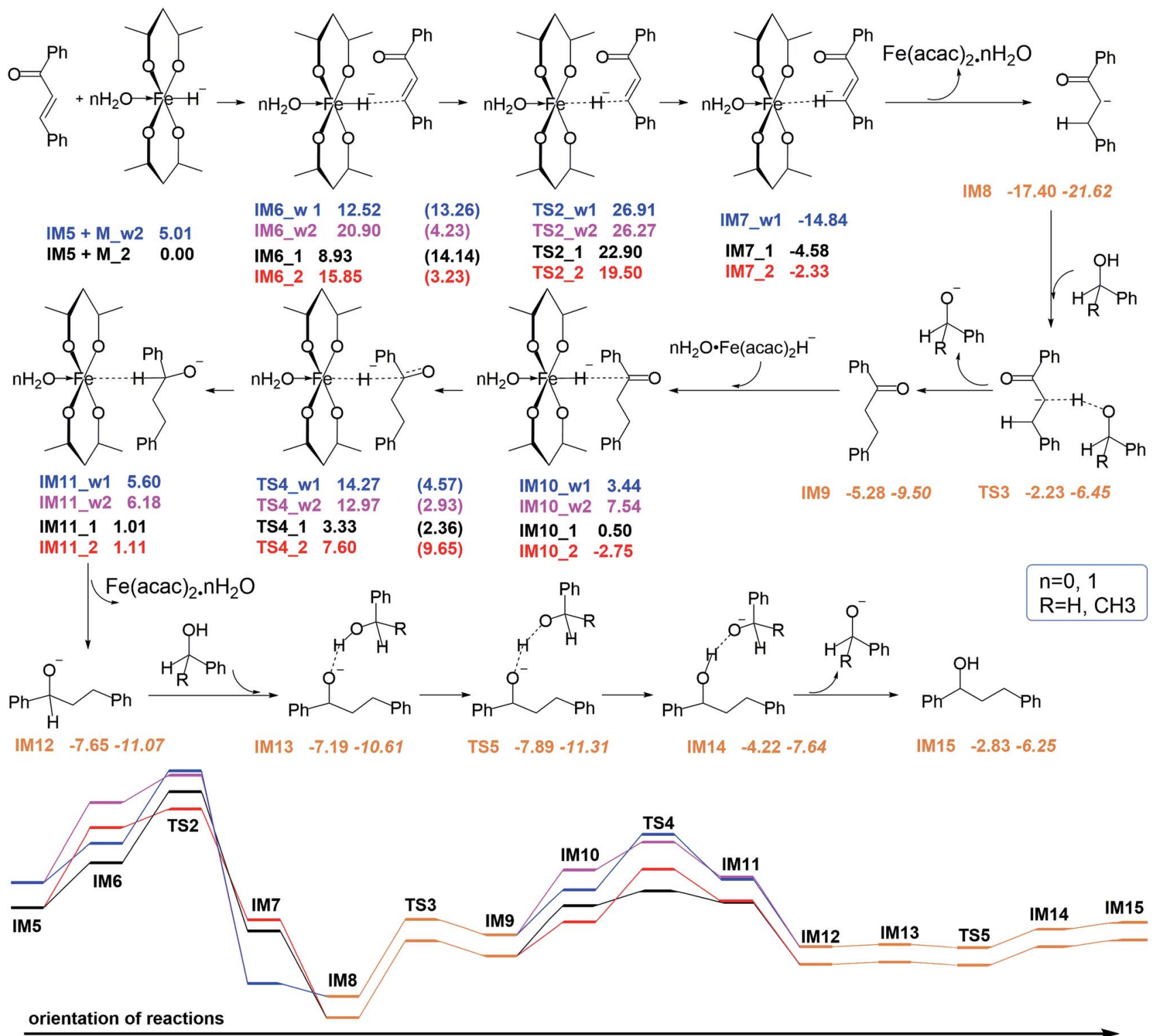

Fig. 3 Four reaction pathways and corresponding free energy profiles of chalcone reduction processes. The orange line represents the process by which the intermediate product abstracts hydrogen protons, regardless of the catalyst, and the energy in italics corresponds to the path without water. The numbers in parentheses refer to the activation barriers.

\section{Results and discussion}

\section{Catalyst initiation}

This reactant system includes 1-phenylethanol, benzyl alcohol, $\mathrm{Fe}(\mathrm{acac})_{2}$ and base $(\mathrm{NaOH})$. First, the base accelerates the ionization of the 1-phenylethanol and benzyl alcohol, which give the 1-phenylethanol anion (R1) and benzyl alcohol anion (R2) respectively. Then, iron-catalyst, come into effect with 1phenylethanol anion and benzyl alcohol anion to form the substrate-catalyst complexes by sigma complexation between the $\mathrm{H}$ and Fe. The optimized geometries of the intermediates and transition with selected pivotal parameters are illustrated in Fig. 2. As shown in Fig. 2, the phenethyl alcohol anion forms a complex with $\mathrm{Fe}(\mathrm{acac})_{2}$ in two different conformations, IM1_1 and IM1_2, followed by the corresponding two kinds of significant differences in the transition state TS1_1 and TS1_2. For TS1_1, the two hydrogen atoms of the alcohol anion points to the oxygen atom of the ligand. While for TS1_2, the benzene ring is almost parallel to the ligand plane. We refer to these two conformations as type I and type II conformations, respectively, and apply them to the discussion of the conformation of compounds appearing below. The distance of $\mathrm{Fe}-\mathrm{H}$ in type II $(1.728 \AA)$ is shorter than that of type I $(1.742 \AA)$. This situation also applies to benzyl alcohol anions. As a control, reactions with water participation are also shown in Fig. 2. As an abbreviation of water, if letter "w" appears in the name of the compound, it means that there is reaction water involved, and this applies to the nomenclature of all the compounds herein. When water participates, the $\mathrm{Fe}-\mathrm{H}$ distance in the transition state is shortened, and the $\mathrm{Fe}-\mathrm{H}$ distance in type II is shorter. 


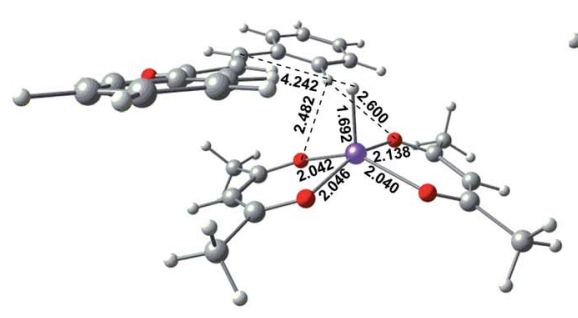

IM6_1
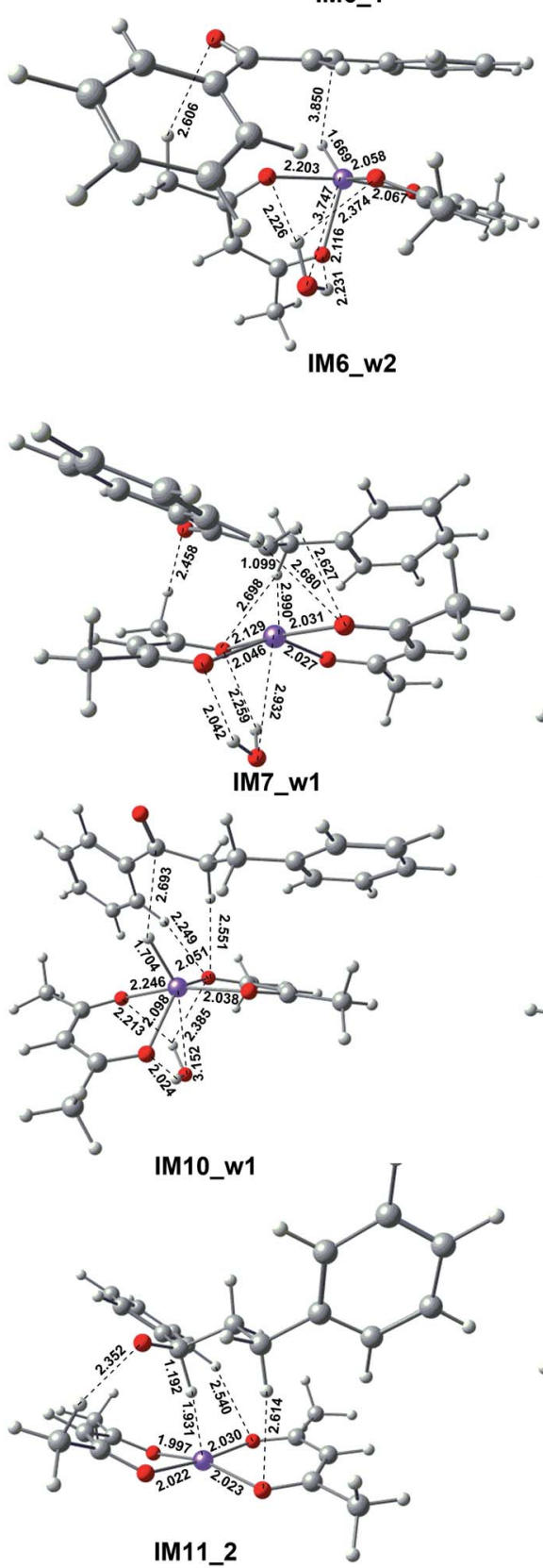
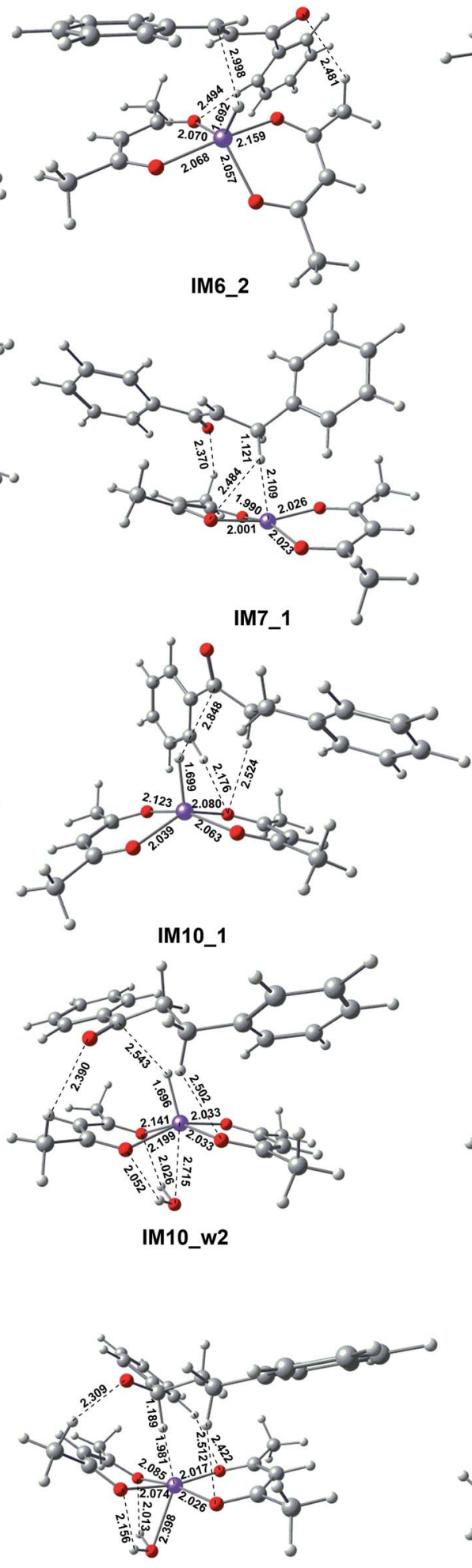

IM11_w1
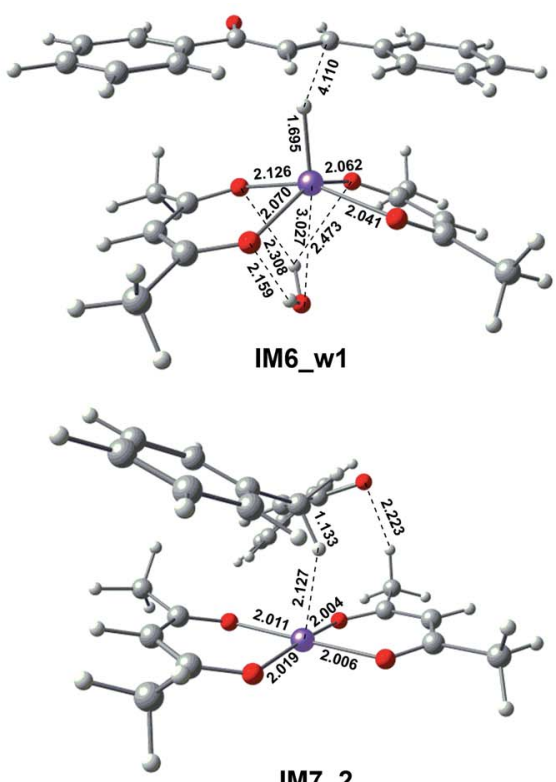

IM7_2
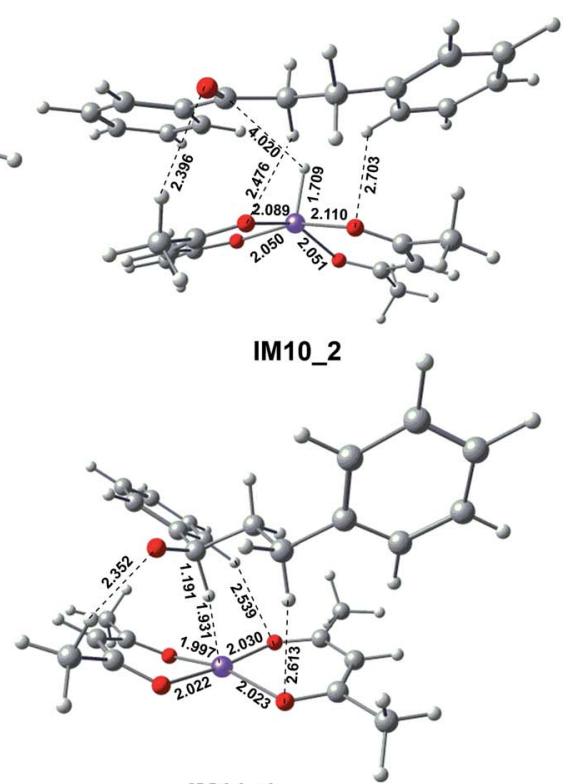

IM11_1

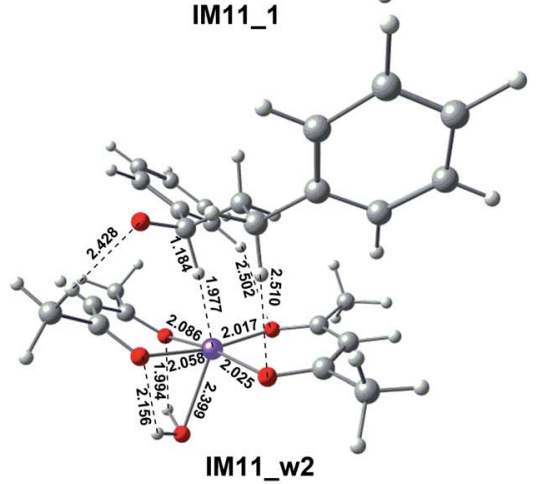

Fig. 4 The geometries of the optimized intermediates correspond to those in Fig. 3 with selected bond distances (in $\AA$ ).

For TS1_w4, the distance of $\mathrm{H}_{2} \mathrm{O}-\mathrm{Fe}$ is the shortest, and the strong effect between the water and Fe causing the effects of $\mathrm{Fe}$ and $\mathrm{H}$ to be greatly weakened, and the distance of the $\mathrm{Fe}-\mathrm{O}$ $(2.686 \AA)$ is the longest among all transition states.
Free energy profiles for the 1-phenylethanol anion (R1) and benzyl alcohol anion (R2) oxidation via the inner-sphere hydrogen transfer pathways are illustrated in Fig. 1. In the absence of water, the barrier of reaction energy in Fig. 1 is in the 

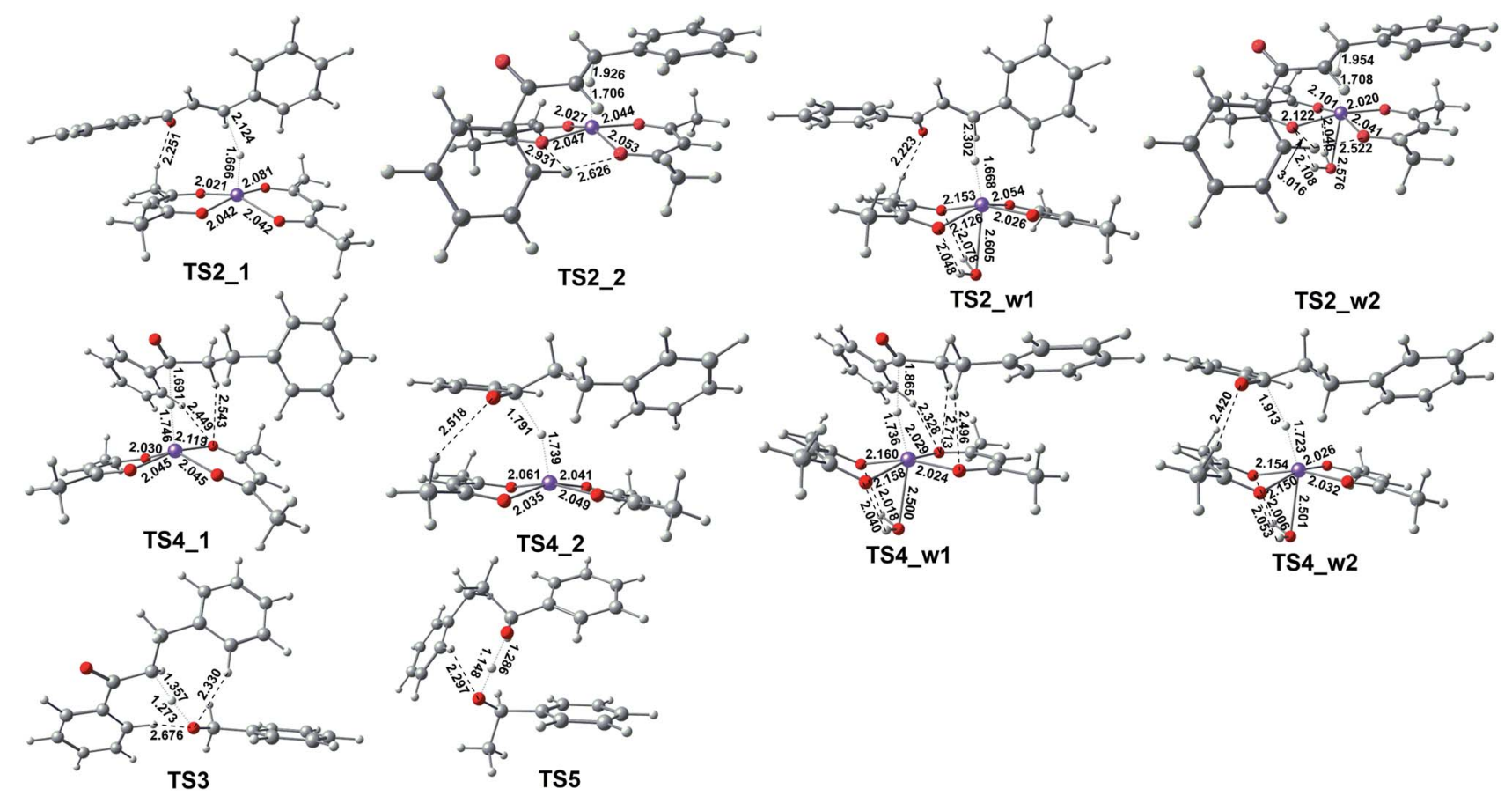

Fig. 5 The geometries of the optimized transition states correspond to those in Fig. 3 with selected bond distances (in Å).

range of 2.48 to $4.53 \mathrm{kcal} \mathrm{mol}^{-1}$. As a control, the reaction energy barrier for water participation is in the range of 4.24 to $5.53 \mathrm{kcal} \mathrm{mol}^{-1}$. It can be seen that the presence of water hardly affects the hydrogen atoms transfer from alcohol anion to the Fe of catalyst. This is because the reaction core areas of the two cases are very similar to each other.

\section{Cross-aldol condensation}

The intermediate products acetophenone (IM4_1) and benzaldehyde (IM4_2) can undergo aldol condensation without the catalyst in an alkaline environment to form chalcone. The mechanism has been detailed studied in our previous study, ${ }^{21}$ so in this article, we will not focus on this process.

In our previous study, we illuminate the details of the mechanism aspects of the ferrocenecarboxaldehyde-catalyzed cross-coupling reaction of 1-phenylethanol with benzyl alcohol based on the density functional theory (DFT) at the M06-2X level of the theory. It should be noted that this reaction system only required inexpensive and commercially available ferrocenecarboxaldehyde and a catalytic amount of $\mathrm{NaOH}$ without sacrificial agent (hydrogen acceptors or hydrogen donors) and complex nitrogen or phosphorus ligands. The intermediate products acetophenone and benzaldehyde can undergo aldol condensation without catalyst in an alkaline environment to form chalcone. The formation of new $\mathrm{C}-\mathrm{C}$ bond from cross-coupling reaction has been studied in detail. On account of the similar feature of benzyl alcohol anion and 1phenylethanol anion, we use the benzyl alcohol anion as the research object to participate in reaction. This part begins with acetophenone transfers a hydrogen proton to benzyl alcohol anion to form the acetophenone anion via the first transition state with the barrier of $0.3 \mathrm{kcal} \mathrm{mol}^{-1}$. Then the acetophenone anion will attack benzaldehyde to form of a new anion intermediate via the second transition state with the barrier of $0.9 \mathrm{kcal} \mathrm{mol}^{-1}$. Then a hydrogen proton transfer from benzyl alcohol to this anion intermediate to form a new electrically neutral intermediate via the third transition state with the barrier of $-0.7 \mathrm{kcal} \mathrm{mol}^{-1}$. After the generation of this electrically neutral intermediate, benzyl alcohol anion enters this reaction process again to capture a hydrogen proton to form another new anion intermediate and benzyl alcohol via the fourth transition state with the barrier of $0.8 \mathrm{kcal} \mathrm{mol}^{-1}$. Then benzyl alcohol will provide a hydrogen proton to this anion intermediate to form intermediate chalcone with fifth transition state with the barrier of $11.5 \mathrm{kcal} \mathrm{mol}^{-1}$.

\section{Chalcone reduction}

After the generation of chalcone (IM5), which is a conjugated planar macromolecule containing both $\mathrm{C}=\mathrm{O}$ and $\mathrm{C}=\mathrm{C}$ double bonds, iron hydride species (M_2 or M_w2), benzyl alcohol and phenylethyl alcohol enter the hydrogen transfer process. The reaction mechanism and the energy are depicted in Fig. 3. First, the $\mathrm{H}$ atom on Fe attacks the unsaturated $\mathrm{C}$ to form the first step hydrogen reduction intermediate product. Then this reduction product can take hydrogen protons from the benzyl alcohol or phenyl ethanol of the reactants, and realize the second step hydrogen reduction.

If the reaction stops at this step, dihydrochalcone will accumulate. In fact, dihydrochalcone was indeed experimentally detected from the product. As the reaction continues, the carbonyl will be reduced. The reduction process is also a hydrogenation catalyst that first provides a hydride ion to carbon, and then this hydrogenation intermediate product abstracts hydrogen protons from benzyl alcohol and 


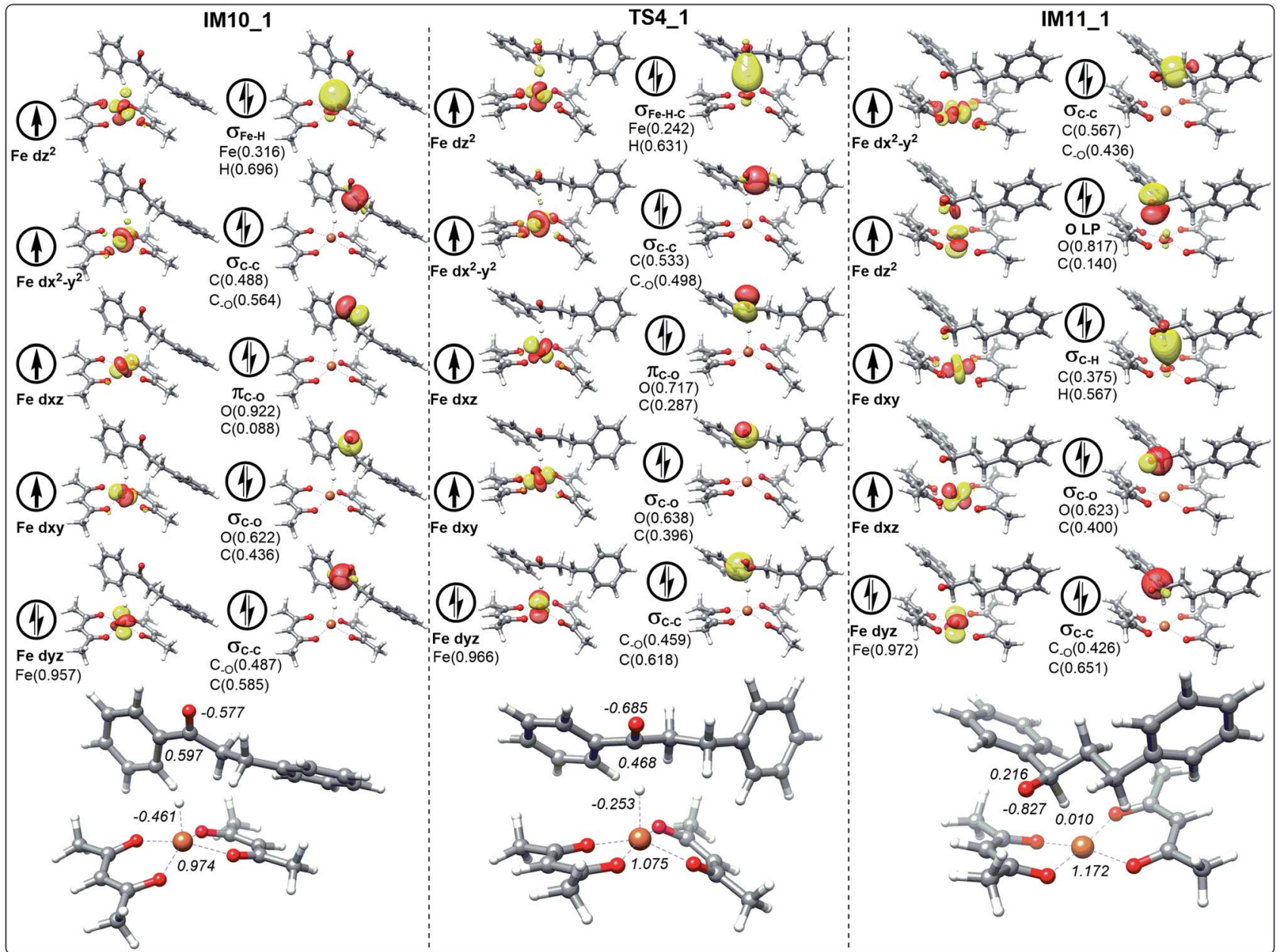

Fig. 6 The schematic frontier molecular orbitals (including the composition) of hydrogen transfer corresponding to IM10_1, TS4_1 and IM11_1 involving the path without water. The values in italic represent the NPA charges of $\mathrm{Fe}, \mathrm{H}, \mathrm{C}$ and $\mathrm{O}$.

phenylethanol. The two sets of corresponding transition states with slightly different energy barrier (TS3_1 $\left(17.25 \mathrm{kcal} \mathrm{mol}^{-1}\right)$, TS3_2 (15.17 kcal mol $\left.{ }^{-1}\right)$, TS5_1 $\left(-0.70 \mathrm{kcal} \mathrm{mol}^{-1}\right)$ and TS5_2 $\left.\left(-2.84 \mathrm{kcal} \mathrm{mol}^{-1}\right)\right)$ when benzyl alcohol and phenylethyl alcohol were used as donors for hydrogen protons. Thus we selected one set to make the energy change line graph of Fig. 3 for more concise. The intermediate products and transition state structures are shown in Fig. 4 and 5.

As shown in Fig. 5, the first step hydrogenation transition configurations of chalcone catalytic belong to type II, with the difference that the benzene ring parallel to the catalyst is close to the carbonyl group. The distance of $\mathrm{H}_{2} \mathrm{O}-\mathrm{Fe}$ in the transition state TS2_w1 (2.605 ̊) and the transition state TS2_w2 (2.576 ̊) indicates that the water and $\mathrm{Fe}$ have a stronger effect. As a result, the distance of $\mathrm{Fe}-\mathrm{H}$ and $\mathrm{H}-\mathrm{C}$ is longer than that without water. It is worth noting that these two transitional states generate the same intermediate IM7_w1. We are pleased to find that the presence of water also hardly affects the reaction energy barrier (about $14 \mathrm{kcal} \mathrm{mol}^{-1}$ and $5 \mathrm{kcal} \mathrm{mol}^{-1}$ ) of the first step hydrogenation of chalcone. Then through the transition state TS3, the chalcone is reduced to dihydrochalcone, and the original conjugated macrosystem is destroyed (Fig. 5). The transitional state of catalytic hydrogenation of dihydrochalcone simultaneously contains both type I and type II structures. The distance of $\mathrm{H}_{2} \mathrm{O}-\mathrm{Fe}$ in the type I transition state TS4_w1 $(2.500$ $\AA$ ) and the type II transition state TS2_w2 (2.501 ̊) indicates that the water and Fe have a stronger effect. The distance of $\mathrm{H}_{2} \mathrm{O}$-Fe in the type I transition state TS4_w1 and the type II transition state TS4_w2 is quite equal to $2.5 \AA$, which is obviously shorter than that of other aqueous transition states. This shows that the water-catalyst interaction is stronger in this step hydrogenation reduction reaction, and can most significantly affect the reaction. The type I transition state without water is the lowest energy barrier $\left(2.83 \mathrm{kcal} \mathrm{mol}^{-1}\right)$, and the energy barrier is raised to $10.83 \mathrm{kcal} \mathrm{mol}^{-1}$ when water is present. On the contrary, the type II transition energy barrier $\left(10.35 \mathrm{kcal} \mathrm{mol}^{-1}\right.$ ) was reduced to $5.43 \mathrm{kcal} \mathrm{mol}^{-1}$. In summary, the presence of water improves the reaction energy barrier for the catalytic hydrogenation of dihydrochalcone, and the dominant reaction pathways have also been interchanged (from type I to type II). The final step of the reaction is a hydrogen proton of the hydroxyl on the phenethyl alcohol transfer process to create 1,3-diphenyl-1-propanol. This procedure proceeds by transition state TS5 to produce the product. The barrier height via TS5 is 


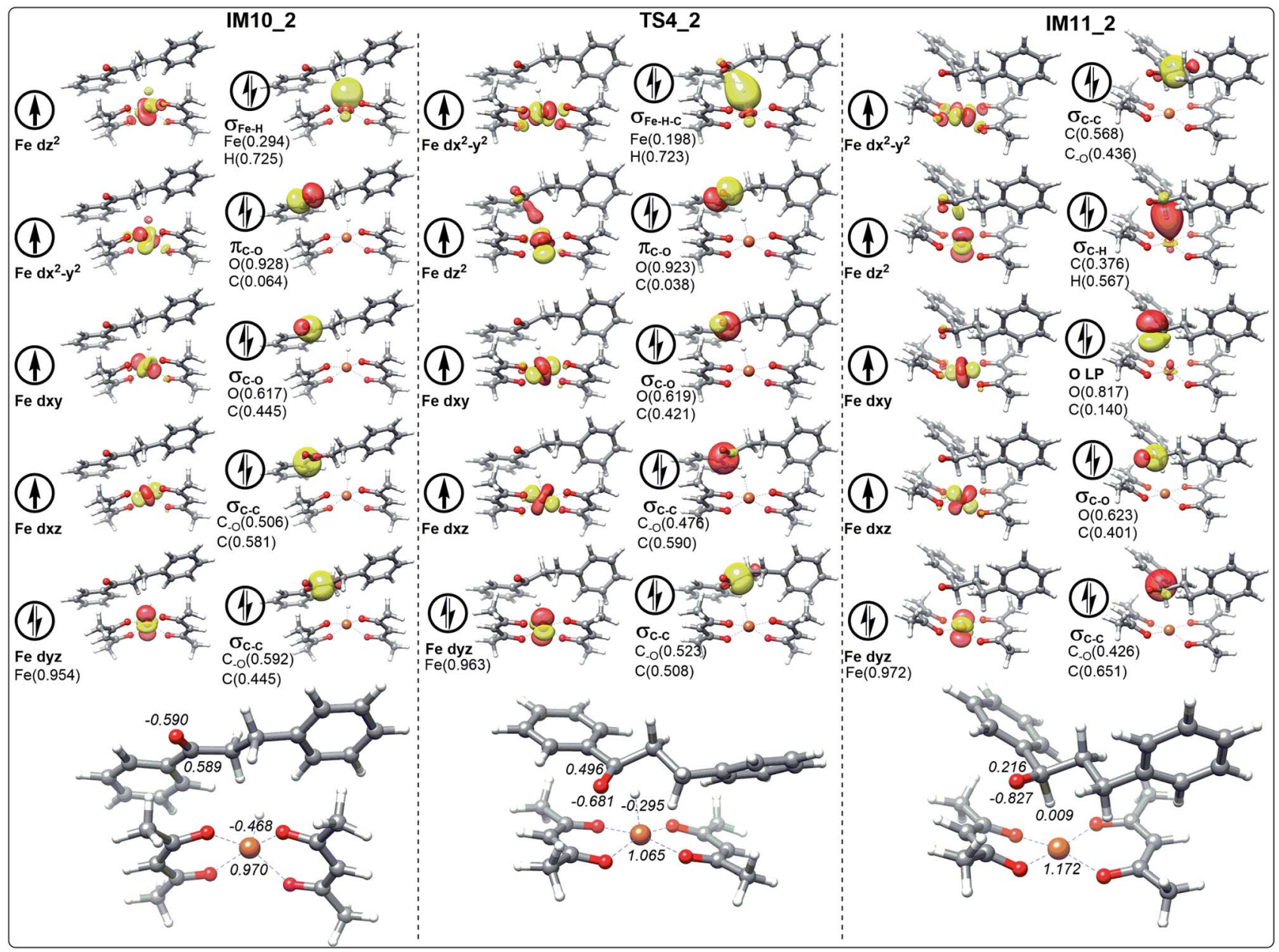

Fig. 7 The schematic frontier molecular orbitals (including the composition) of hydrogen transfer corresponding to IM10_2, TS4_2 and IM11_2 involving the path without water. The values in italic represent the NPA charges of Fe, H, C and O.

measured to be $-0.7 \mathrm{kcal} \mathrm{mol}^{-1}$. Since the product of all the reaction is mainly alcohol, it is quite fit with the experimental result.

\section{Electronic structure analysis}

In the process of dihydrochalcone reduction, the critical step is the catalytic hydrogenation of carbonyl (the process from IM10 to IM11 involving TS4 shown in Fig. 3). Detailed electronic structure analysis can provide deep insight for the reactivity of hydrogen transfer. The schematic frontier molecular orbitals (FMOs) corresponding to the process from IM10 to IM11 are shown in Fig. 6-9. In order to concise, the Fig. 6-9 only list the molecular orbitals that are most closely related to the reaction core.

For the ten molecular orbitals of IM10_1 in Fig. 6, the four single-occupied orbitals $\mathrm{d}_{z}{ }^{2}, \mathrm{~d}_{x-y}{ }^{2}{ }^{2}, \mathrm{~d}_{x z}$, and $\mathrm{d}_{x y}$, are the highest occupied orbitals. The remaining six orbitals are the lowerenergy localized dual-occupant molecular orbitals and are ranked in the right-hand column in terms of energy from high to low. As we known, the s-orbitals and the p-orbitals of iron center are double occupancy. The composition of hydrogen in $\sigma_{\mathrm{Fe}-\mathrm{H}}$ orbital is 0.696 , which means that the $\sigma_{\mathrm{Fe}-\mathrm{H}}$ bond is mainly composed of a pair of electrons of hydrogen. This is very helpful to understand that hydrogen has a negative NPA charge of -0.461 . With chalcone close to the catalyst, hydrogen gradually moves away from the $\mathrm{Fe}$ center and approaches the carbonyl carbon. The NPA charge of Fe in transition state TS4_1 increases to 1.075. In contrast, the charge of carbonyl carbon decreases to 0.468 and increases to 0.287 in the composition of $\pi_{\mathrm{C}-\mathrm{O}}$ orbital. We also found that the composition of carbonyl carbon in the $\sigma_{\mathrm{C}-\mathrm{O}}$ and $\sigma_{\mathrm{C}-\mathrm{C}}$ orbitals is decreasing, which indicates that the electron delocalization of carbonyl carbon is decreasing. Subsequently, the electrons transfer from $\sigma_{\mathrm{Fe}-\mathrm{H}-\mathrm{C}}$ to $\sigma_{\mathrm{C}-\mathrm{H}}$ intensifies to the transition of carbonyl carbon from $\mathrm{sp}^{2}$ hybrid to $\mathrm{sp}^{3}$ hybrid. In IM11-1, the lone electron pairs of carbonyl oxygen have been concentrated on $\mathrm{O}$ p-orbital, resulting in the disappearance of $\pi_{\mathrm{C}-\mathrm{O}}$ bond and the decrease of its NPA charge to -0.827 . It is found that in the newly formed $\sigma_{\mathrm{C}-\mathrm{H}}$ orbital, the composition of hydrogen is higher than that of carbon, but the NPA charge of carbon decreases to 0.216 , and the charge of hydrogen increases to a positive 0.010 . This is because the electronegativity of carbon is stronger than that of hydrogen, causing the $\sigma_{\mathrm{C}-\mathrm{H}}$ orbital to move toward carbon. In Fig. 7, 8 and 9, the process of hydrogen transfer to carbonyl carbon is very similar. 


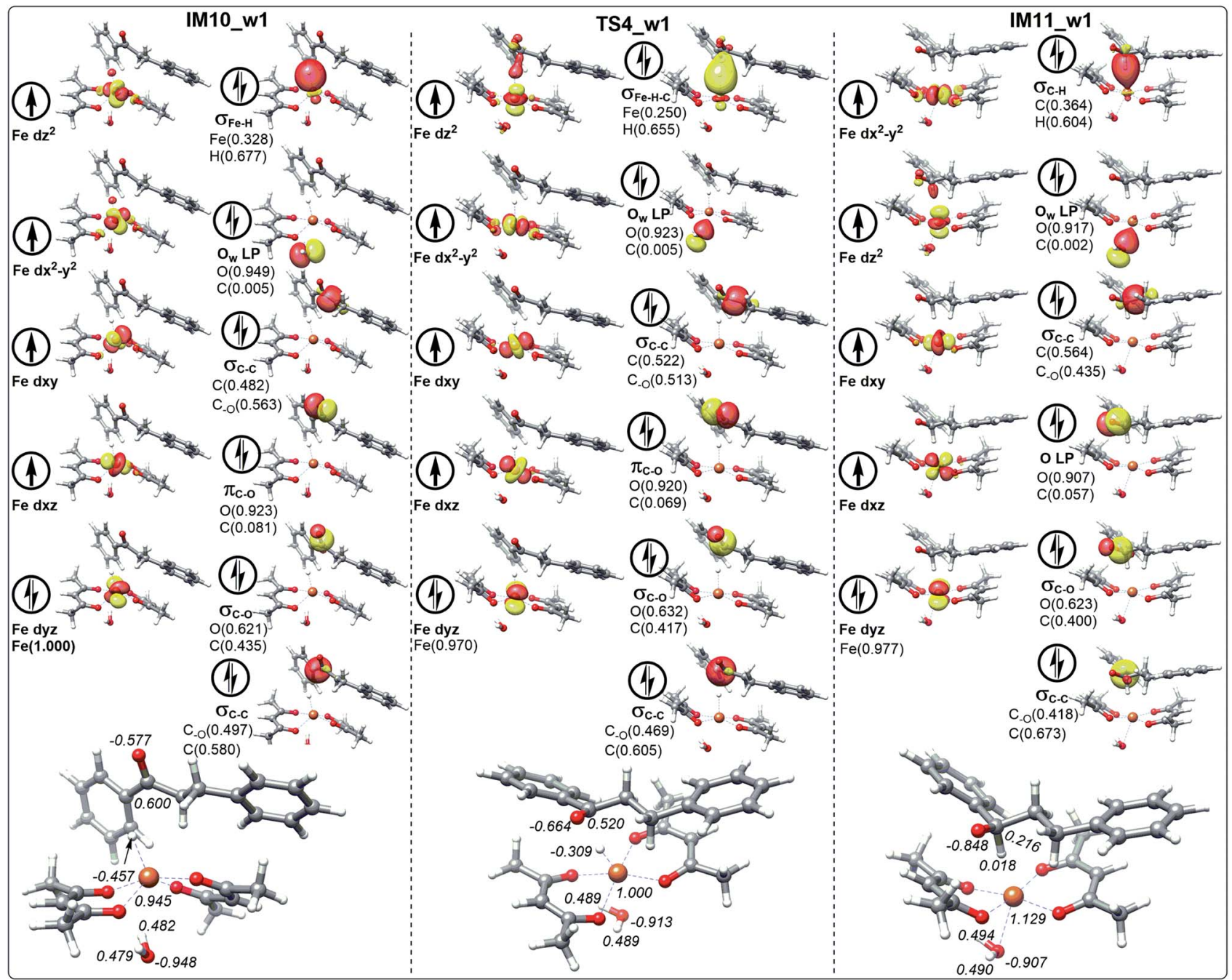

Fig. 8 The schematic frontier molecular orbitals (including the composition) of hydrogen transfer corresponding to IM10_W1, TS4_W1 and IM11_w1 involving the path with water. The values in italic represent the NPA charges of Fe, H, C and O.

It is worth noting that the NPA charge of Fe in Fig. 8 (Fig. 9) is smaller than that in Fig. 6 (Fig. 7) due to water presence. The ten molecular orbitals of IM10_2 (TS4_2) are very similar to those of IM10_1 (TS4_1) except that the order of $\sigma_{\mathrm{C}-\mathrm{C}}$ orbital becomes lower than the $\pi_{\mathrm{C}-\mathrm{O}}$ and $\sigma_{\mathrm{C}-\mathrm{O}}$ orbitals. This may be due to the interaction of the oxygen atoms of dihydrochalcone with the hydrogen atoms on the catalyst.

Fig. 8 and 9 show the schematic frontier molecular orbitals of the reactions with water participation. It can be observed that $\mathrm{O}$ atom of water molecular interacts with Fe center $(2.500 \AA)$ to form a coordination bond through $\mathrm{O}$ p-orbital $\left(\mathrm{O}_{\mathrm{w}} \mathrm{LP}\right)$ in TS4_w1 and TS4_w2. Similarly, in the reactions of hydrogen transfer corresponding to the path with water participation also proceeds via hydrogen anion transfer process. The orbital energy of $\mathrm{O}_{\mathrm{w}} \mathrm{LP}$ is only lower than that of $\sigma_{\mathrm{Fe}-\mathrm{H}}$ of IM10_w1 in Fig. 8. By comparing TS4_w1 and TS4_1 with their pre-complexes IM10_w1 and IM10_1, it can be seen that the orbital order does not change when water is present. It is worth noting that in contrast to Fig. 6, 7 and 8, the $\sigma_{\mathrm{Fe}-\mathrm{H}}$ orbital in Fig. 9 is no longer the energy highest among double occupancy molecular orbitals, which results in a lower energy barrier.

\section{Design of catalysts for the production of dihydrochalcone}

To our knowledge, dihydrochalcone has been established as effective compounds for a number of pharmaceutical applications, such as antidiabetic, antimalaria, antibacterial, antifungal, anti-inflammatory and anti-tumor drugs. ${ }^{33-39}$ It is desirable if the reaction can stay at the dihydrochalcone stage. Therefore we focus on the catalysts for the production of dihydrochalcone. Through all the discussions above, three important points can be found:

(1) Although the adsorption energy of water and catalyst is positive and thermodynamically unfavorable, the value of about $5 \mathrm{kcal} \mathrm{mol}^{-1}$ indicates that water can be easily adsorbed to the catalyst. When the hydride ion is transferred to the center iron of the catalyst, the $\mathrm{H}_{2} \mathrm{O}-\mathrm{Fe}$ bond is significantly elongated (from 2.219 to $3.048 \AA$ ). At this point, the interaction between water and catalyst is almost entirely a weak hydrogen 


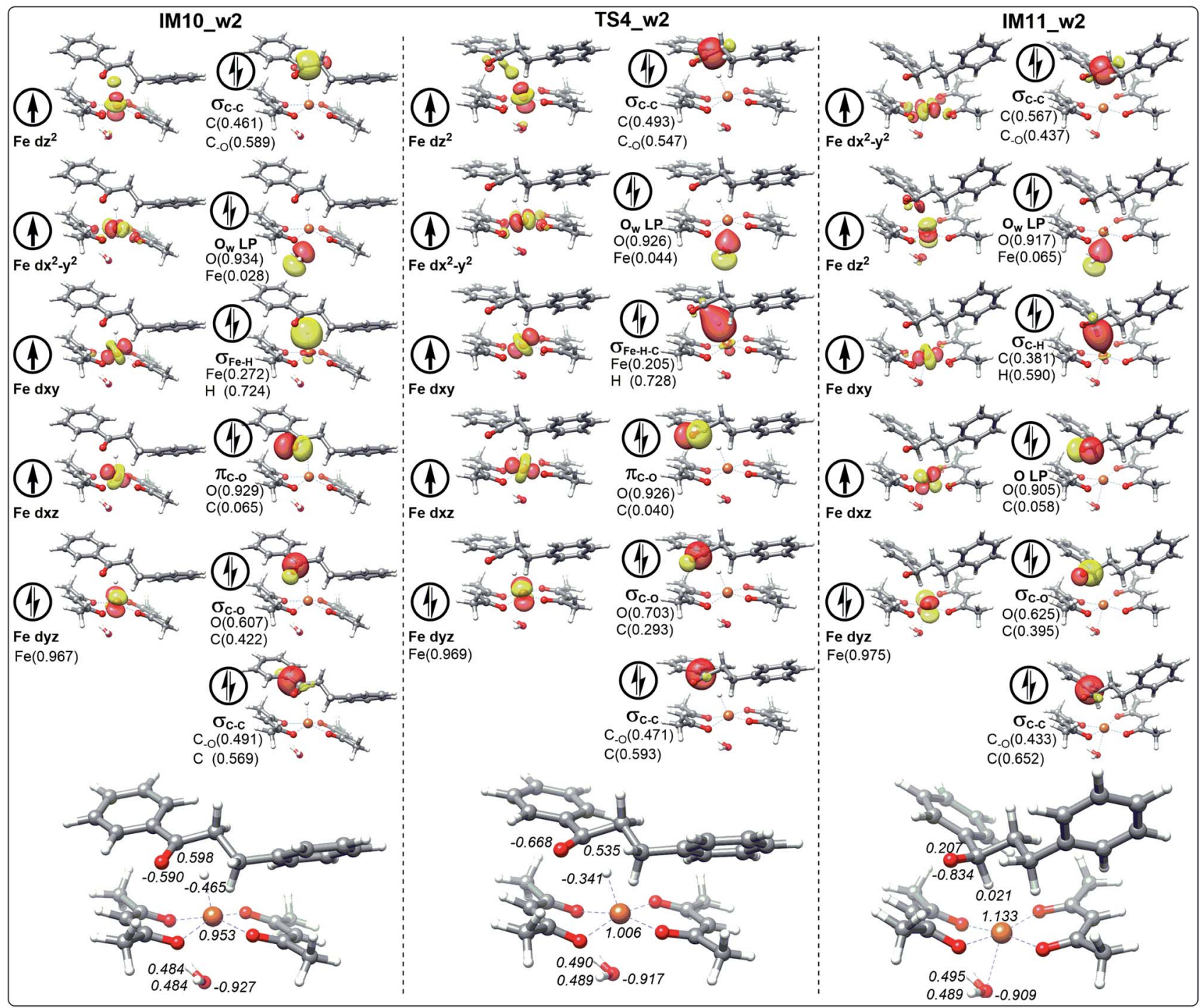

Fig. 9 The schematic frontier molecular orbitals (including the composition) of hydrogen transfer corresponding to IM10_W2, TS4_W2 and IM11_w2 involving the path with water. The values in italic represent the NPA charges of Fe, H, C and O.

bond between water's hydrogen and ligand oxygen (it can be seen from the water's orientation and $\mathrm{O}-\mathrm{H}$ bond length). This case also applies to the catalytic process.

(2) The interaction between water and iron center in transition state is stronger than that in the pre-complexes. It shows that the $\mathrm{H}_{2} \mathrm{O}-\mathrm{Fe}$ bond length is shorter, and the water's p orbital clearly points to the iron center in transition states. Compared to other transition states, the interaction in TS4_w1 and TS4_w2 are enhancive since their $\mathrm{H}_{2} \mathrm{O}$-Fe bond lengths are shorter (very consistent equals to $2.500 \AA$ ).

(3) In the presence of water, the reduction energy barriers of dihydrochalcone, IM9, are affected in the three groups containing H-anion transfer processes (IM1 $\rightarrow$ TS1, IM6 $\rightarrow$ TS2 and IM10 $\rightarrow$ TS4). It is obviously that the energy barriers in the first two groups are barely affected, and the last group is the critical step. In this step, the reduction energy barrier of type I is increased to $10.83 \mathrm{kcal} \mathrm{mol}^{-1}$, and it is greater than the inverse reaction energy barrier of $8.67 \mathrm{kcal} \mathrm{mol}^{-1}$. While the reduction energy barrier of type II is reduced to $5.53 \mathrm{kcal} \mathrm{mol}^{-1}$, which is less than the inverse reaction energy barrier of $6.79 \mathrm{kcal} \mathrm{mol}^{-1}$. It can be seen that the type I reaction favors to stay in the dihydrochalcone.

Based on the above three points of discussion, we can modify the acetylacetonate ferrous catalyst to make the reaction stay at the dihydrochalcone stage. The theoretically designed catalysts, M_3 and $M_{\_} 4$, based on acetylacetonate ferrous are shown in Fig. 10. They have three outstanding advantages: (1) the methyl group on the catalyst ligand is replaced with a $\mathrm{C}=\mathrm{C}$ double bond, which avoids the type II reaction and expands the electron delocalization of the ligand to stabilize the catalyst; (2) the change of $\mathrm{O}-\mathrm{Fe}$ distance can be easily achieved by flexible alkanes twisting. When the hydride ion is transferred to the center iron of M_3 or M_4, the O-Fe distance is as long as 3.800 $\AA$ or $3.663 \AA$. While there is no $\mathrm{H}$ anion, the O-Fe distance is only $2.607 \AA$ or $2.283 \AA$; (3) the reaction core Fe is in semienveloping state, which makes the catalyst's applicability and anti-interference stronger.

Finally, we also found that the benzene ring is far from the reaction core (the metal atom in the catalyst center) and is also 

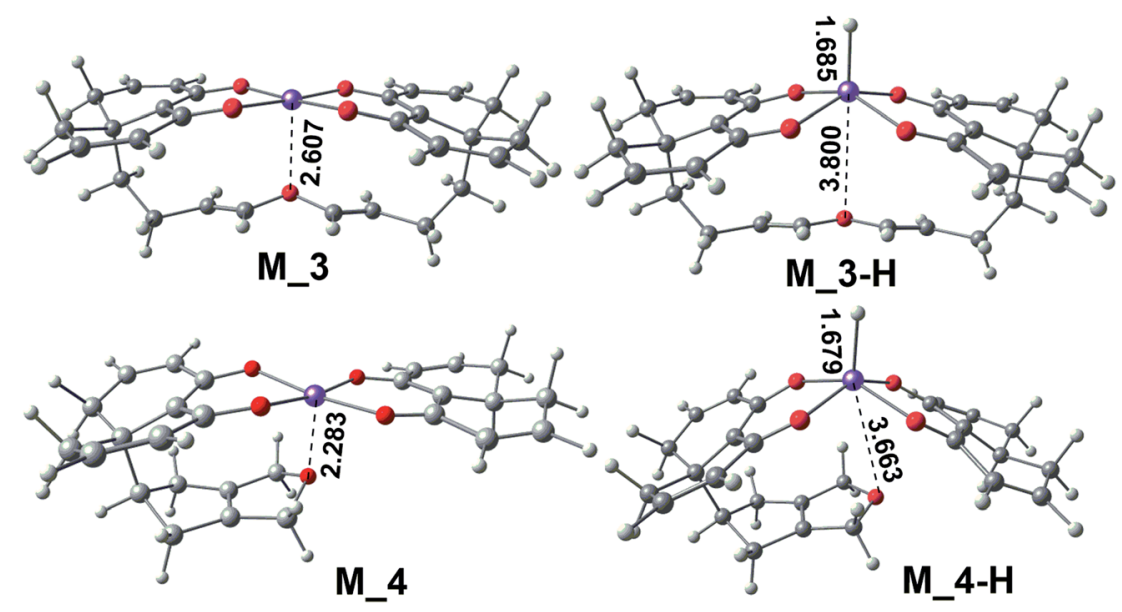

Fig. 10 Two dihydrochalcone catalysts were designed on the basis of chemical reactions in $\beta$-alkylation reaction proceeds.

almost unaffected by the catalyst. This is also the reason why acetylacetonate catalysts can catalyze the alkylation of alcohols with substituents (such as halogen and alkoxy groups) on the benzene ring. The catalysts we design should also have good catalytic effects on the derivatives of such alcohols.

\section{Conclusions}

In this calculation, we illuminate the details of the mechanism aspects of the $\mathrm{Fe}(\mathrm{acac})_{2}$-catalyzed cross-coupling reaction of 1phenylethanol with benzyl alcohol based on the density functional theory (DFT) includes the effect of paraxylene solvent effect. It should be noted that this reaction system only required inexpensive and commercially available $\mathrm{Fe}(\mathrm{acac})_{2}$ and a catalytic amount of $\mathrm{NaOH}$ without sacrificial agent (hydrogen acceptors or hydrogen donors) and complex nitrogen or phosphorus ligands. The following findings can be revealed by our calculation. (1) The catalyzed reaction consists of three steps: hydride transfer from $\alpha$-C of benzyl alcohol and 1-phenylethanol accompanied by the electron transfer; cross-coupling reaction to generate new $\mathrm{C}-\mathrm{C}$ bond; and the reduction step with the migration of hydrogen from metal hydride (M_1 or M_w1) and benzyl alcohol, leading to the generation of product. (2) The energy of the entire cycle indicates that the activation barriers for the hydrogen abstraction are a very low, under $5 \mathrm{kcal} \mathrm{mol}^{-1}$, but it is quite fit for the experiment conditions. (3) The only by-product water has only clearly influenced the reduction of the intermediate dihydrochalcone. Detailed electronic structure analysis was performed to achieve a deep insight for this step. (4) Based on these results, two dihydrochalcone catalysts were designed on the basis of chemical reactions in $\beta$-alkylation reaction proceeds.

\section{Conflicts of interest}

There are no conflicts to declare.

\section{Acknowledgements}

The authors thank the National Natural Science Foundation of China (No. 21573090, No. 21403086), and Scientific Research
Fund of Jilin Provincial Education Department (2015437) for financial support of this research. Project of Scientific Research Development of Shandong Universities (Grant No. J17KB076). Science and Technology Research Project of Jilin Provincial Department of Education in 12th Five-Year Plan (No. 388[2011]).

\section{References}

1 A. Gradillas, E. Belmonte, R. F. da Silva and J. Pérez-Castells, Eur. J. Org. Chem., 2014, 2014, 1935-1941.

2 S. O. Poelma, G. L. Burnett, E. H. Discekici, K. M. Mattson, N. J. Treat, Y. Luo, Z. M. Hudson, S. L. Shankel, P. G. Clark and J. W. Kramer, J. Org. Chem., 2016, 81, 7155-7160.

3 J. Yang, J. Zhang, T. T. Chen, D. M. Sun, J. Li and X. F. Wu, Chin. Chem. Lett., 2011, 22, 1391-1394.

4 J.-H. Fan, J. Yang, R.-J. Song and J.-H. Li, Org. Lett., 2015, 17, 836-839.

5 A. Nakatani, K. Hirano, T. Satoh and M. Miura, Chem.-Eur. J., 2013, 19, 7691-7695.

6 J. Jin and D. W. MacMillan, Nature, 2015, 525, 87-90.

7 P. Liu, R. Liang, L. Lu, Z. Yu and F. Li, J. Org. Chem., 2017, 82, 1943-1950.

8 P. Paul, P. Bhanja, N. Salam, U. Mandi, A. Bhaumik, S. M. Alam and S. M. Islam, J. Colloid Interface Sci., 2017, 493, 206-217.

9 W. Bai and G. Jia, Inorg. Chim. Acta, 2015, 431, 234-241.

10 J. s. Campos, J. n. López-Serrano, E. Álvarez and E. Carmona, J. Am. Chem. Soc., 2012, 134, 7165-7175.

11 T. Matsuda and I. Yuihara, Chem. Commun., 2015, 51, 73937396.

12 G. Li, X. Ma, C. Jia, Q. Han, Y. Wang, J. Wang, L. Yu and S. Yang, Chem. Commun., 2017, 53, 1261-1264.

13 Z.-Z. Zhou, F.-S. Liu, D.-S. Shen, C. Tan and L.-Y. Luo, Inorg. Chem. Commun., 2011, 14, 659-662.

14 L. D. Tran and O. Daugulis, Org. Lett., 2010, 12, 4277-4279.

15 E. R. Fruchey, B. M. Monks and S. P. Cook, J. Am. Chem. Soc., 2014, 136, 13130-13133.

16 Q. Yang, P. Wu, J. Chen and Z. Yu, Chem. Commun., 2014, 50, 6337-6339. 
17 T. Yan, B. L. Feringa and K. Barta, Nat. Commun., 2014, 5, 5602.

18 S. Elangovan, J. B. Sortais, M. Beller and C. Darcel, Angew. Chem., Int. Ed., 2015, 54, 14483-14486.

19 J. Yang, X. Liu, D. L. Meng, H. Y. Chen, Z. H. Zong, T. T. Feng and K. Sun, Adv. Synth. Catal., 2012, 354, 328-334.

$20 \mathrm{H}$. Xu, Master thesis, Jilin University, 2016.

21 P. Y. Qin, W. Feng, R. Wang, H. Y. Zhao, H. L. Liu, X. R. Huang and K. Sun, Polyhedron, 2016, 111, 179-184.

22 M. J. Frisch, G. W. Trucks, H. B. Schlegel, G. E. Scuseria, M. A. Robb, J. R. Cheeseman, G. Scalmani, V. Barone, B. Mennucci, G. A. Petersson, H. Nakatsuji, M. Caricato, X. Li, H. P. Hratchian, A. F. Izmaylov, J. Bloino, G. Zheng, J. L. Sonnenberg, M. Hada, M. Ehara, K. Toyota, R. Fukuda, J. Hasegawa, M. Ishida, T. Nakajima, Y. Honda, O. Kitao, H. Nakai, T. Vreven, J. A. Montgomery Jr, J. E. Peralta, F. Ogliaro, M. Bearpark, J. J. Heyd, E. Brothers, K. N. Kudin, V. N. Staroverov, R. Kobayashi, J. Normand, K. Raghavachari, A. Rendell, J. C. Burant, S. S. Iyengar, J. Tomasi, M. Cossi, N. Rega, J. M. Millam, M. Klene, J. E. Knox, J. B. Cross, V. Bakken, C. Adamo, J. Jaramillo, R. Gomperts, R. E. Stratmann, O. Yazyev, A. J. Austin, R. Cammi, C. Pomelli, J. W. Ochterski, R. L. Martin, K. Morokuma, V. G. Zakrzewski, G. A. Voth, P. Salvador, J. J. Dannenberg, S. Dapprich, A. D. Daniels, O. Farkas, J. B. Foresman, J. V. Ortiz, J. Cioslowski and D. J. Fox, Gaussian 09, Revision D.01, Gaussian, Inc., Wallingford CT, 2009.

23 Y. Zhao and D. G. Truhlar, J. Chem. Phys., 2006, 125, 194101. 24 K. Fukui, Acc. Chem. Res., 1981, 14, 363-368.
25 F. Neese, Wiley Interdiscip. Rev.: Comput. Mol. Sci., 2012, 2, 73-78.

26 L. Goerigk and S. Grimme, J. Chem. Theory Comput., 2011, 7, 291-309.

27 S. Grimme, S. Ehrlich and L. Goerigk, J. Comput. Chem., 2011, 32, 1456-1465.

28 S. Grimme, J. Antony, S. Ehrlich and H. Krieg, J. Chem. Phys., 2010, 132, 154104.

29 F. Weigend and R. Ahlrichs, Phys. Chem. Chem. Phys., 2005, 7, 3297-3305.

30 F. Neese, J. Am. Chem. Soc., 2006, 128, 10213-10222.

31 E. F. Pettersen, T. D. Goddard, C. C. Huang, G. S. Couch, D. M. Greenblatt, E. C. Meng and T. E. Ferrin, J. Comput. Chem., 2004, 25, 1605-1612.

32 Y. Zhao, N. Mahaja and J. Y. Fang, Small, 2006, 2, 364-367. 33 W. Lesse, Gynecol. Obstet. Invest., 1902, 15, 680-693.

34 J. Nelson and R. Falk, Anticancer Res., 1993, 13, 2287-2292. 35 J. Nelson and R. Falk, Anticancer Res., 1993, 13, 2293-2299. 36 Y. Nakamura, S. Watanabe, N. Miyake, H. Kohno and T. Osawa, J. Agric. Food Chem., 2003, 51, 3309-3312.

37 C. Echeverria, J. F. Santibanez, O. Donoso-Tauda, C. A. Escobar and R. Ramirez-Tagle, Int. J. Mol. Sci., 2009, 10, 221-231.

38 L. Norton, R. A. DeFronzo and M. A. Abdul-Ghani, US Endocrinology, 2010, 6, 42-47.

39 M. V. B. Reddy, H. Y. Hung, P. C. Kuo, G. J. Huang, Y. Y. Chan, S. C. Huang, S. J. Wu, S. L. Morris-Natschke, K. H. Lee and T. S. Wu, Bioorg. Med. Chem. Lett., 2017, 27, 1547-1550. 